\title{
Reverse osmosis influence over the content of metals and organic acids in low alcoholic beverages
}

\author{
Mitică Tiberiu Andrieş ${ }^{1}$, Cătălin Ioan Zamfir ${ }^{2}$, Camelia Elena Luchian ${ }^{1}$, Marius Niculaua ${ }^{2}$, Cintia Colibaba ${ }^{1}$, \\ Gheorghe Odăgeriu ${ }^{2}$, Mihai Cristian Focea ${ }^{1}$, and Valeriu V. Cotea ${ }^{1, a}$ \\ ${ }^{1}$ The University of Agricultural Sciences and Veterinary Medicine, 3 M. Sadoveanu Alley, Iaşi 700490, Romania \\ ${ }^{2}$ Research Centre for Oenology, Romanian Academy - Iaşi Branch, 9 M. Sadoveanu Alley, Iaşi 700490, Romania
}

\begin{abstract}
Wine is defined as an alcoholic beverage resulted from fermentation of grape must, having ethanol content higher than $8.5 \%(\mathrm{v} / \mathrm{v})$. Wine consumption has health benefits related to the high concentration of polyphenolic compounds with antioxidant activity and cardiovascular protection effects. However, the alcohol content restricts wine consumption, but wines with low-alcohol content can be obtained with the help of the dealcoholisation process, after it was produced through alcoholic fermentation. The purpose of this work is to evaluate the organic acid concentration, metal content and other physical-chemical parameters of low alcoholic beverages obtained from grape must by a process which involves reverse osmosis, mixing in a variable ratio the permeate and concentrate and then fermentation. For the experiments, a Muscat Ottonel grape must from Iaşi vineyard was used. There were ten variants of beverages (wines) with low alcoholic concentration, by mixing known quantities of the two phases resulting from the reverse osmosis process. These beverages (wines) had an alcoholic concentration starting from $2.5 \%(\mathrm{v} / \mathrm{v})$ in the first variant, up to $7 \%$ $(\mathrm{v} / \mathrm{v})$ in the tenth variant. Alcoholic concentration varies for each variant by $0.5 \%(\mathrm{v} / \mathrm{v})$. After fermentation in $50 \mathrm{~L}$ stainless steel tanks, the samples were filtered with $0.45 \mu \mathrm{m}$ sterile membrane and bottled in $0.75 \mathrm{~L}$ glass bottles. After 2 months of storage at constant temperature, the beverage samples were analyzed to determine the metal content (AAS method), organic acids concentration (HPLC method), and other physical-chemical characteristics (OIV standard methods). The results obtained indicate that the very complex physical-chemical composition of the low alcoholic beverages analyzed is influenced by the specific chemical composition of a given grape must, as well as by the use of products obtained from reverse osmosis.
\end{abstract}

\section{Introduction}

Wine is an ancient beverage spread all over the world and one of the most known alcoholic drinks, which has the benefit to reduce the risk of cardiovascular diseases, thanks to the many compounds playing a role of great importance human health-wise [1].

For the past several years there has been a steady increase of the alcoholic degree of wines because of climate change. Because of global warming, grapes that have a higher sugar concentration are produced. For this reason the cultivation of grape varieties is being moved from Southern to cooler areas. This changes every year, depending on various circumstances like occasionally unfavorable climate conditions [2].

An important aspect of wine production is the process of obtaining a certain lower ethanol concentration, which has gained considerable attention over the last 10 years. Increase consumer demand for wines that are perceived as healthier, changing attitudes of consumers regarding the social consequences of excessive ethanol consumption and more favorable excise rates for lower alcohol beverage are just some of the reasons for lowering ethanol levels in wine. There is a significant consumer demand for the beverages with lower ethanol levels [3].

a e-mail: vvcotea@yahoo.com
Metals in wine occur at the $\mathrm{mg} / \mathrm{L}$ level or less. Though not directly related to the taste of the wine, the metal content should be determined because excess is undesirable, and in some cases prohibited, due to potential toxicity. Lead content in wine, to guarantee consumer health protection is restricted in several states by legislation because toxicity for human health [4].

For reason of direct correlation with soil composition, metals appear to be the best way to identify the geographical origin of the wine [5]. Moreover, knowledge of the metallic ion concentration of wine is of interest because of their influence on the wine-making process where metals such as calcium, potassium, copper and iron can cause cloudiness or precipitates.

The international community set some low acceptance levels for some metals, due to their importance in nutrition and their potentially toxic effects [6].

In grapes, the total acid content normally reaches a maximum content during growth and decreases during ripening. [7] Although having the same genotype, grapes harvested from different climates, have different organic acid contents. [8] During grape ripening, in continuous warm conditions a lower acid content at maturity results mostly due to increasing degradation of malic acid [9]. Malic and tartaric acids are dominant organic acids and account for $90 \%$ or more of the total acids in grapes [10]. 
Table 1. Classical enological parameters of low alcoholic wine obtained by reverse osmosis.

\begin{tabular}{|c|c|c|c|c|c|c|c|c|c|c|}
\hline Parameter & VSA 1 & VSA 2 & VSA 3 & VSA 4 & VSA 5 & VSA 6 & VSA 7 & VSA 8 & VSA 9 & VSA 10 \\
\hline Alcoholic strength (\% v.a.) & 2.5 & 3.2 & 3.7 & 4.1 & 4.7 & 5.1 & 5.7 & 6.2 & 6.7 & 7.2 \\
\hline Sugars $(g / L)$ & 0.19 & 0.58 & 1.36 & 0.68 & 1.32 & 4.37 & 3.24 & 5.21 & 6.29 & 6.28 \\
\hline $\mathrm{VA}\left(\mathrm{g} / \mathrm{L} \mathrm{C} \mathrm{C}_{2} \mathrm{H}_{4} \mathrm{O}_{2}\right)$ & 0.39 & 0.42 & 0.42 & 0.54 & 0.51 & 0.45 & 0.54 & 0.51 & 0.51 & 0.51 \\
\hline $\mathrm{TA}\left(\mathrm{g} / \mathrm{L} \mathrm{C} \mathrm{C}_{4} \mathrm{H}_{6} \mathrm{O}_{6}\right)$ & 5.15 & 5.35 & 5.47 & 5.69 & 5.88 & 6.07 & 6.19 & 6.22 & 6.3 & 6.45 \\
\hline pH & 3.85 & 3.63 & 3.52 & 3.46 & 3.35 & 3.24 & 3.22 & 3.19 & 3.10 & 3.02 \\
\hline Free $\mathrm{SO}_{2}(\mathrm{mg} / \mathrm{L})$ & 40.96 & 40.96 & 38.40 & 43.52 & 35.84 & 38.40 & 35.84 & 35.84 & 35.84 & 33.28 \\
\hline Total $\mathrm{SO}_{2}(\mathrm{mg} / \mathrm{L})$ & 53.76 & 56.32 & 48.64 & 51.20 & 48.64 & 56.32 & 51.20 & 48.64 & 53.76 & 48.64 \\
\hline Density & 0.9982 & 0.9982 & 0.9984 & 0.9972 & 0.9973 & 0.9986 & 0.9973 & 0.9978 & 0.9978 & 0.9978 \\
\hline $\mathrm{NE}$ & 4.71 & 6.82 & 8.44 & 7.32 & 9.28 & 10.83 & 10.66 & 11.49 & 12.21 & 13.82 \\
\hline
\end{tabular}

VA - (volatile acidity); TA - (total acidity); NE- (non-reducing extract); VSA-“ low alcoholic wine”.

Table 2. Instrumental parameters.

\begin{tabular}{lcccccccccc}
\hline Element/ Parameters & $\mathbf{Z n}$ & $\mathbf{F e}$ & $\mathbf{C u}$ & $\mathbf{N i}$ & $\mathbf{P b}$ & $\mathbf{M n}$ & $\mathbf{M g}$ & $\mathbf{C a}$ & $\mathbf{N a}$ & $\mathbf{K}$ \\
\hline$\lambda(\mathbf{n m})$ & 213.857 & 371.993 & 324.754 & 352.454 & 405.781 & 403.076 & 285.213 & 396.847 & 589.592 & 769.897 \\
\hline Nebulizer Flow (L/min) & 0.45 & 0.65 & 0.7 & 0.7 & 0.75 & 0.9 & 0.9 & 0.6 & 0.95 & 0.75 \\
\hline Air Injection Flow Rate & medium & high & high & high & high & high & medium & high & high & high \\
\hline Read Time (s) & 3 & 3 & 3 & 3 & 3 & 3 & 3 & 3 & 3 & 3 \\
\hline
\end{tabular}

All organic acids play an important role in wine, the taste being influenced by the concentration of different organic acids. Wine's organic acids in wine are malic, tartaric, citric, acetic, lactic, succinic and others. Concentration of organic acids varies depending on different factors such as $\mathrm{pH}$, temperature, sulfur dioxide and oxygen concentration. The ratio of tartaric acid to malic acid mainly influences the taste of the wine. When the ratio of these acids is about 2 or less, the wine will not be harmonious and will have a sour aftertaste. The wine with best flavor and bouquet will be obtained at a ratio of tartaric to malic acid equal to 3 and more. For example succinic acid has a salty-bitter taste, citric acid gives freshness to wine and malic acid gives the taste of green apples [11].

A complete analysis of wine composition is a timeconsuming process, but it brings necessary information for both obtaining a quality product and its maintenance under proper conditions. Therefore, only a few parameters are checked periodically. Among them, the most common are: alcoholic degree, reducing sugars, $\mathrm{pH}$, sulfur dioxide, total and volatile acidity.

The classical methods used for monitoring the wine composition with high robustness and precision are recognized by the international community as official methods of analysis, even though more recent methods may be based on modern automated instrumental techniques [12].

\section{Materials and method}

\subsection{Grape sample and winemaking}

Muscat Ottonel grapes from Iasi vineyard were harvested in 2015 at optimal maturity. The grapes were destemmed and crushed, and must was transferred in stainless steel containers. The grape must was concentrated until $308.3 \mathrm{~g} / \mathrm{L}$ sugar using a device for reverse osmosis, Bucher Vaslin. The obtained permeate has $8.032 \mathrm{~g} / \mathrm{L}$ sugar.

There were obtained ten variants of beverages (wines) with low alcoholic concentration, by using known quantities of the two phases resulting from the reverse osmosis process. These beverages (wines) had an alcoholic concentration starting from $2.5 \%(\mathrm{v} / \mathrm{v})$ in the first variant, up to $7 \%(\mathrm{v} / \mathrm{v})$ in the tenth variant (VSA1 to VSA10). Alcoholic concentration varies for each variant by $0.5 \%$ $(\mathrm{v} / \mathrm{v})$. After fermentation in $50 \mathrm{~L}$ stainless steel tanks (Zymaflore $\mathrm{X} 16^{\circledR}$ yeast), the samples were filtered with $0.45 \mu \mathrm{m}$ sterile membrane, and bottled in $0.75 \mathrm{~L}$ glass bottles.

After 2 months of storage at constant temperature, the beverage samples were analyzed to determine the metal content (using an Agilent MP-AES 4200), organic acids concentration (HPLC method), and other physicalchemical characteristics (OIV standard methods).

\subsection{Physical-chemical analysis}

The main physico-chemical parameters analyzed were alcoholic strength, reducing sugars, total acidity (TA), volatile acidity (VA), real acidity $(\mathrm{pH})$, sulfur dioxide and density (O.I.V., 2016).

The results are presented in Table 1.

\subsection{Analysis of the metals content in wines}

All analyzed samples were diluted to reduce the salinity of the samples under $1 \%$. If this technique is used, the mineralization and ionization of the sample is not necessary. The measurements were performed using an Agilent MP-AES 4200 instrument equipped with the standard sample introduction system consisting of the OneNeb nebulizer, double pass cyclonic spray chamber and easy fit torch.

The Agilent SPS-3 auto-sampler was used to deliver samples to the instrument allowing automatic operation. Selection of optimal lines depended on wavelengths that were free from spectral interference and matched the appropriate sensitivity. Spectral and background interferences were simultaneously and accurately corrected using the MP software.

Each sample was analyzed for three times and the registration time was 3 seconds. In Table 2 are shown the instrumental parameters and operating conditions of the equipment. 


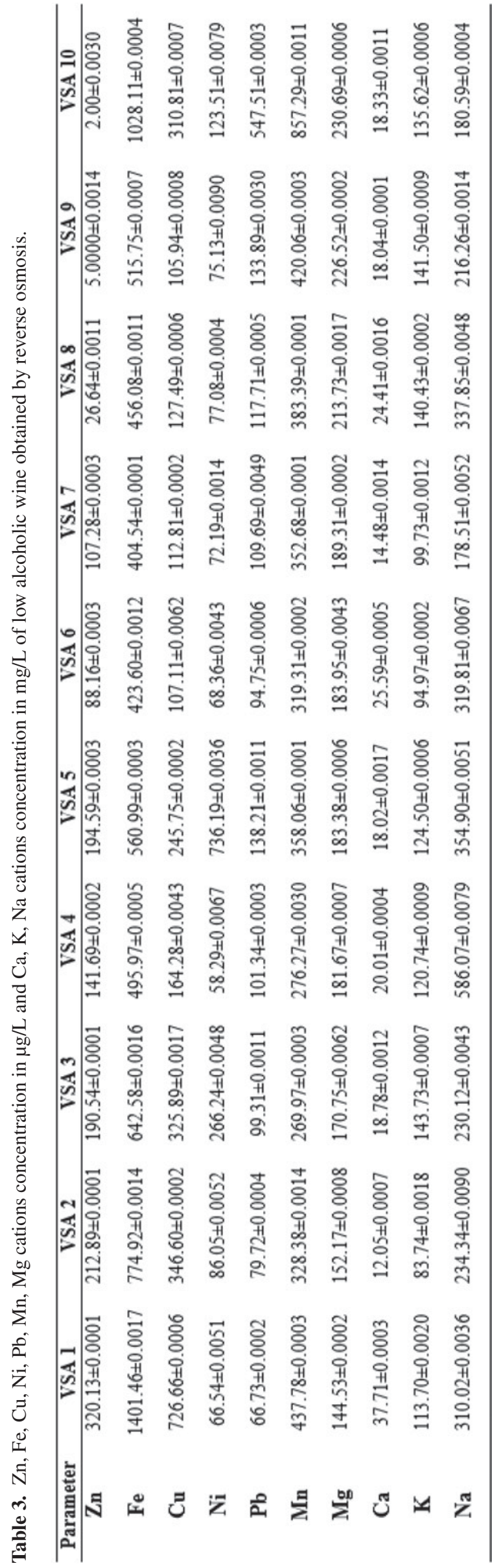

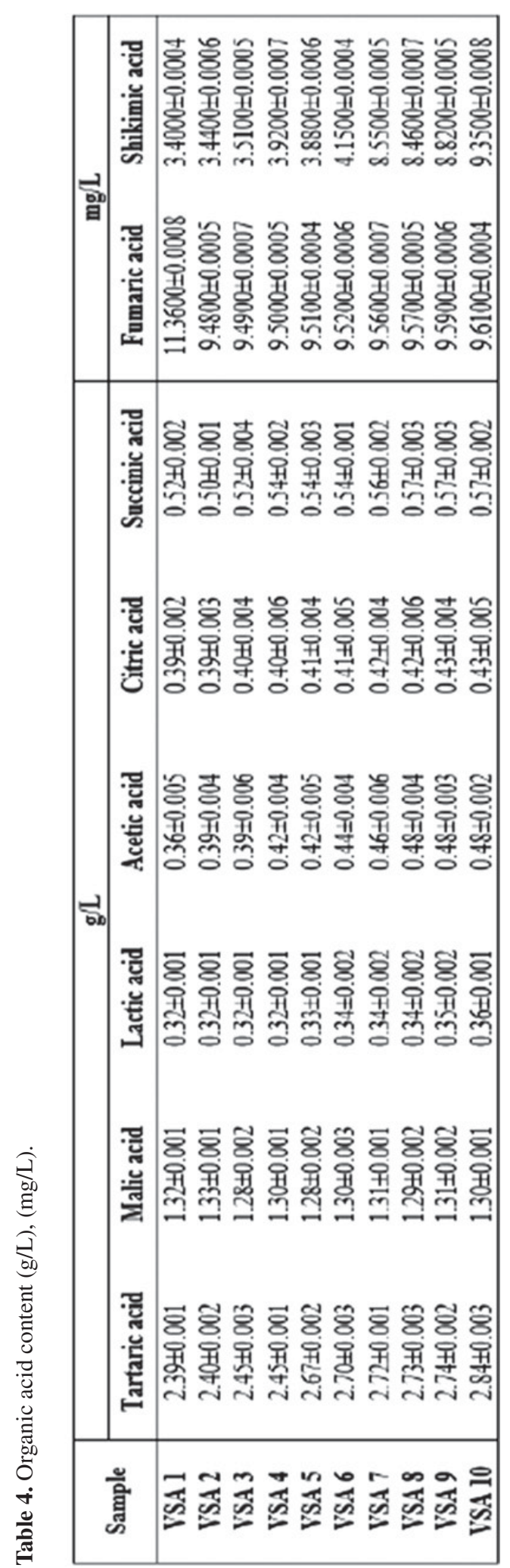

2.4. Analysis of the organic acids in wines using HPLC-High-performance liquid chromatography method

For the analysis of the organic acids content a Shimadzu series Proeminence LC20 device was used. The sample was filtered through a $28 \mathrm{~mm}$ diameter nylon $0.45 \mu \mathrm{m}$ 
syringe cartridge. This method is described in the MA-EAS313-04-ACIORG by O.I.V. standards.

Using a $5 \mu \mathrm{L}$ volume of standard, a sample was injected through two analytical columns (YMC-Triart C18 multi-stage hybrid group's $3 \mu \mathrm{m} 150 \times 4.6 \mathrm{~mm} 120 \AA$ ) at a flow rate of $0.9 \mathrm{~mL} / \mathrm{min}$., using a solution of sulphuric acid adjusted to a value of $1.3 \mathrm{pH}$.

Columns' temperatures were maintained at $45^{\circ} \mathrm{C}$ for the entire period of analysis.

\section{Results and discussion}

Statistical evaluation of the data was performed using Statgraphics Centurion XVI ${ }^{\circledR}$ software, (StatPoint Technologies, Inc, U.S.A.). In this study, a one-way ANOVA procedure was applied.

\subsection{Physical-chemical characteristics of wine}

For alcoholic strength, there was significant difference between all samples. In the first variant, were obtained wines with $2.5 \%$ alcohol degree. Then every sample has an alcoholic degree with $0.5 \%$ volume more than the previous one.

Total acidity (TA) also showed similar mean values for all samples, with a minimum in the first sample and with a maximum in the last variant.

All other parameters showed average values with variability to a smaller or larger degree depending on the impact of different quantities of permeate and concentrate used for every wine sample.

All of the wine samples were dry.

\subsection{Metals content of wine sample}

The values of $\mathrm{Zn}, \mathrm{Fe}, \mathrm{Cu}, \mathrm{Ni}, \mathrm{Pb}, \mathrm{Mn}, \mathrm{Mg}, \mathrm{Ca}, \mathrm{K}, \mathrm{Na}$, cations content identified in samples of low alcoholic wine, as determined by AES, are shown in Table 3.

The measured concentration of zinc, iron, copper, nickel show that these varied with a minimum content in the first sample VSA and then increased gradually in other samples.

Magnesium and calcium concentration in wine have an insignificant change in all analyzed samples.

The lead value progressively increases from the first VSA1 sample to VSA5 with a minimum content of $66.73 \mu \mathrm{g} / \mathrm{L}$ and a maximum content of $138.21 \mu \mathrm{g} / \mathrm{L}$. This increase is then found again starting with VSA6 with a minimum content of $94.75 \mu \mathrm{g} / \mathrm{L}$ and a maximum content in the 10th VSA10 sample of $547.51 \mu \mathrm{g} / \mathrm{L}$.

The content of manganese fluctuates in large limits, with a minimum content in VSA3 sample of $269.97 \mu \mathrm{g} / \mathrm{L}$ and a maximum content in VSA10, of $857.29 \mu \mathrm{g} / \mathrm{L}$.

Potassium cations concentration values present small differences from one sample to another.

Sodium concentrations fluctuates, registering a minimum content in the case of the seventh sample VSA7 $178.51 \mathrm{mg} / \mathrm{L}$ and a maximum of $586.07 \mathrm{mg} / \mathrm{L}$ in the fourth sample VSA4. This increase was not linear since the first sample, but fluctuated.
Table 5. Multiple Range Tests for Malic Acid by Sample.

\begin{tabular}{lccc} 
Contrast & Sig. & Difference & +/- Limits \\
\hline VSA 1. - VSA 10. & & 0 & 0.00295 \\
VSA 1. - VSA 2. & $*$ & -0.03 & 0.00295 \\
VSA 1. - VSA 3. & $*$ & 0.04 & 0.00295 \\
VSA 1. - VSA 4. & $*$ & 0.01 & 0.00295 \\
VSA 1. - VSA 5. & $*$ & 0.02 & 0.00295 \\
VSA 1. - VSA 6. & $*$ & 0.03 & 0.00295 \\
VSA 1. - VSA 7. & $*$ & -0.01 & 0.00295 \\
VSA 1. - VSA 8. & $*$ & 0.04 & 0.00295 \\
VSA 1. - VSA 9. & $*$ & -0.01 & 0.00295 \\
VSA 10. - VSA 2. & $*$ & -0.03 & 0.00295 \\
VSA 10. - VSA 3. & $*$ & 0.04 & 0.00295 \\
VSA 10. - VSA 4. & $*$ & 0.01 & 0.00295 \\
VSA 10. - VSA 5. & $*$ & 0.02 & 0.00295 \\
VSA 10. - VSA 6. & $*$ & 0.03 & 0.00295 \\
VSA 10. - VSA 7. & $*$ & -0.01 & 0.00295 \\
VSA 10. - VSA 8. & $*$ & 0.04 & 0.00295 \\
VSA 10. - VSA 9. & $*$ & -0.01 & 0.00295 \\
VSA 2. - VSA 3. & $*$ & 0.07 & 0.00295 \\
VSA 2. - VSA 4. & $*$ & 0.04 & 0.00295 \\
VSA 2. - VSA 5. & $*$ & 0.05 & 0.00295 \\
VSA 2. - VSA 6. & $*$ & 0.06 & 0.00295 \\
VSA 2. - VSA 7. & $*$ & 0.02 & 0.00295 \\
VSA 2. - VSA 8. & $*$ & 0.07 & 0.00295 \\
VSA 2. - VSA 9. & $*$ & 0.02 & 0.00295 \\
VSA 3. - VSA 4. & $*$ & -0.03 & 0.00295 \\
VSA 3. - VSA 5. & $*$ & -0.02 & 0.00295 \\
VSA 3. - VSA 6. & $*$ & -0.01 & 0.00295 \\
VSA 3. - VSA 7. & $*$ & -0.05 & 0.00295 \\
VSA 3. - VSA 8. & & 0 & 0.00295 \\
VSA 3. - VSA 9. & $*$ & -0.05 & 0.00295 \\
VSA 4. - VSA 5. & $*$ & 0.01 & 0.00295 \\
VSA 4. - VSA 6. & $*$ & 0.02 & 0.00295 \\
VSA 4. - VSA 7. & $*$ & -0.02 & 0.00295 \\
VSA 4. - VSA 8. & $*$ & 0.03 & 0.00295 \\
VSA 4. - VSA 9. & $*$ & -0.02 & 0.00295 \\
VSA 5. - VSA 6. & $*$ & 0.01 & 0.00295 \\
VSA 5. - VSA 7. & $*$ & -0.03 & 0.00295 \\
VSA 5. - VSA 8. & $*$ & 0.02 & 0.00295 \\
VSA 5. - VSA 9. & $*$ & -0.03 & 0.00295 \\
VSA 6. - VSA 7. & $*$ & -0.04 & 0.00295 \\
VSA 6. - VSA 8. & $*$ & 0.01 & 0.00295 \\
VSA 6. VSA 9. & $*$ & -0.04 & 0.00295 \\
VSA 8. & $*$ & 0.05 & 0.00295 \\
VSA & & 0 & 0.00295 \\
VSA & & -0.05 & 0.00295 \\
\hline
\end{tabular}

\subsection{Wine organic acids analysis}

The descendent $\mathrm{pH}$ values of the analyzed samples are concordance whit the weight of each acid, in accordance with the literature [13].

ANOVA table decomposes the variability for all acids identified (Table 4) into contributions due to various factors. Since Type III sums of squares (the default) have been chosen, the contribution of each factor is measured having removed the effects of all other factors.

The P-values test the statistical significance of each of the factors. Since one P-value (0.00) is less than 0.05, this factor has a statistically significant effect on all acids identified at the $95.0 \%$ confidence level. 
Table 6. The homogenous groups that were identified.

\begin{tabular}{lllll}
\hline Sample & Count & LS Mean & LS Sigma & Homogeneous Groups \\
\hline VSA 8. & 3 & 1.86 & 0.001 & $\mathrm{X}$ \\
VSA 3. & 3 & 1.86 & 0.001 & $\mathrm{X}$ \\
VSA 6. & 3 & 1.87 & 0.001 & $\mathrm{X}$ \\
VSA 5. & 3 & 1.88 & 0.001 & $\mathrm{X}$ \\
VSA 4. & 3 & 1.89 & 0.001 & $\mathrm{X}$ \\
VSA 10. & 3 & 1.9 & 0.001 & $\mathrm{X}$ \\
VSA 1. & 3 & 1.9 & 0.001 & $\mathrm{X}$ \\
VSA 9. & 3 & 1.91 & 0.001 & $\mathrm{X}$ \\
VSA 7. & 3 & 1.91 & 0.001 & $\mathrm{X}$ \\
VSA 2. & 3 & 1.93 & 0.001 & $\mathrm{X}$ \\
\hline
\end{tabular}

Table 7. Table of Least Squares Means for Malic Acid with $95.0 \%$ confidence Intervals.

\begin{tabular}{llllll}
\hline Level & Count & Mean & $\begin{array}{l}\text { Stnd. } \\
\text { Error }\end{array}$ & $\begin{array}{l}\text { Lower } \\
\text { Limit }\end{array}$ & $\begin{array}{l}\text { Upper } \\
\text { Limit }\end{array}$ \\
\hline GRAND MEAN & 30 & 1.891 & & & \\
\hline Sample & & & & & \\
VSA 1. & 3 & 1.9 & 0.001 & 1.89791 & 1.90209 \\
VSA 10. & 3 & 1.9 & 0.001 & 1.89791 & 1.90209 \\
VSA 2. & 3 & 1.93 & 0.001 & 1.92791 & 1.93209 \\
VSA 3. & 3 & 1.86 & 0.001 & 1.85791 & 1.86209 \\
VSA 4. & 3 & 1.89 & 0.001 & 1.88791 & 1.89209 \\
VSA 5 & 3 & 1.88 & 0.001 & 1.87791 & 1.88209 \\
VSA 6. & 3 & 1.87 & 0.001 & 1.86791 & 1.87209 \\
VSA 7. & 3 & 1.91 & 0.001 & 1.90791 & 1.91209 \\
VSA 8. & 3 & 1.86 & 0.001 & 1.85791 & 1.86209 \\
VSA 9. & 3 & 1.91 & 0.001 & 1.90791 & 1.91209 \\
\hline
\end{tabular}

For example, in Table 5 a multiple comparison procedure was applied to determine which means are significantly different from others in the case of acid malic. The bottom half of the output shows the estimated difference between each pair of means. An asterisk has been placed next to 42 pairs, indicating that these pairs show statistically significant differences at the $95.0 \%$ confidence level.

In Table 6, 7 homogenous groups are identified using columns of X's. Within each column, the levels containing $X$ 's form a group of means within which there are no statistically significant differences. The method currently being used to discriminate among the means is Fisher's least significant difference (LSD) procedure. With this method, there is a $5.0 \%$ risk of calling each pair of means significantly different when the actual difference equals 0 .

In Table 7 are shown the mean malic acid for each level of the factors. It also shows the standard error of each mean, which is a measure of its sampling variability. The rightmost two columns show $95.0 \%$ confidence intervals for each of the means.
For all other parameters, the main effects are statistically significant at the $95.0 \%$ confidence level. This rule is available for all identified acids in all samples.

\section{Conclusion}

The results obtained indicate that the very complex physical-chemical composition of the low alcoholic beverages analyzed is influenced by the specific chemical composition of a given grape must, as well as by the use of products obtained from reverse osmosis.

We found moderate correlation between quantities of permeate and concentrate regarding metals content. The content of metals has not increased in large limits.

The study show the influence of used quantities of the two phases resulting from the reverse osmosis process (permeate/concentrate). These had a statistically significant effect on all acids identified at the $95.0 \%$ confidence level.

\section{References}

[1] L. Liguori, J. Food Chem. 140, 68-75 (2013)

[2] E. Duchene, C. Schneider, J. Dev. Agron. Sustain. 25, 93-99 (2005)

[3] B. Saha, J. Oenoviti Int. Net. Fr. 1, 78-86 (2013)

[4] M. Aceto, O. Abollino, M. C. Bruzzonti, E. Mentasti, C. Sarzanini and M. Malandrino, J. Food Addit. Contam. 19, 126-133 (2002)

[5] P.R. Ashurst \& M. J. Dennis, Food authentication, 60-107 (EDP Chapman \& Hall, 1996)

[6] H. Eschneauer, Am J Enol Vitic 33, 226-230 (1982)

[7] N. A. M. Eskin, H. M. Henderson \& R. J. Townsend, N. A. M. Eskin Biochemistry of foods, 31-63 (EDP Academic Press, 1971)

[8] T. Fuleki, E. Pelayo \& R. Palabay, J. AOAC Int. 76, 591-600 (1993)

[9] Seymour, G.B., Taylor, J.E., Tucker, Gregory A., Biochemistry of fruit ripening, 189-220 (EDP Chapman \& Hall 1993)

[10] T. Philip \& F. E. Nelson. J. Food Sci. 38, 18-20 (1973)

[11] V. N. Bayraktar, J. Biotech. Acta 6, 97-106 (2013)

[12] M. D. Luque de Castro, J. González-Rodríguez, P. Pérez-Juan, J.Food Sci. Technol. 21, 231-265 (2005)

[13] G. Odageriu, Evaluarea solubilitatii compusilor tartrici din vinuri, 169-187 (EDP. "Ion Ionescu de la Brad" Iasi, 2006) 